\title{
Aflatoxins in dates and dates products
}

\begin{abstract}
A total of 153 samples of dates and dates products (date cookies, date cake and date halva) from Punjab and Khyber Pakhtunkhwa, Pakistan were evaluated for aflatoxins (AFs) using HPLC equipped with fluorescence detection. Thirty eight out of 96 samples $(39.6 \%)$ of different date varieties and 18 out of 57 (31.6\%) samples of date products contained AFs. The total mean level of AFs ranged between 2.90 to $4.96 \mu \mathrm{g} / \mathrm{kg}$ and 2.76 to $4.80 \mu \mathrm{g} / \mathrm{kg}$ in dates and dates products, respectively. About 16 and 20 samples of dates were found above the permissible level for AFB1 and total AFs, respectively (i.e. $2 \mu \mathrm{g} / \mathrm{kg}, 4 \mu \mathrm{g} / \mathrm{kg}$ ). Furthermore, two samples of date's cookies and one sample of date cake were found above the level of AFB1 and total AFs and three and five samples of date halva were found above the recommended limit for AFB1 and total AFs, respectively. The high occurrence of AFs may cause health hazards and limit exports.
\end{abstract}

Keyword: Aflatoxins; Date varieties; Dates products; HPLC 